Published in Proceedings of the 8th International Conference on Industrial Technology and Management (ICITM) 2019, Cambridge, United Kingdom, 2-4 March 2019, which should be cited to refer to this work.

DOI:10.1109/ICITM.2019.8710695

\title{
Fieldwork Analysis of Figurants' Involvement in an Airplane Crash Simulation in order to Improve the Realism of the Exercise
}

\author{
The case of Sion International Airport
}

\author{
Emmanuel Fragnière, Benjamin Nanchen, Randolf Ramseyer, Patrick Kuonen, Blaise Larpin, Pierre-Yves Roh, \\ and Rolf Wilk \\ University of Applied Sciences Western Switzerland (HES-SO), Sierre, Switzerland \\ e-mail: emmanuel.fragniere@hevs.ch
}

\begin{abstract}
Aircraft crash simulation is a mandatory exercise for all international airports. The procedure of such a simulation is that a set of figurants play out a given plane crash scenario. Then, all professional bodies-such as police, fire brigades, medical care professionals, airport staff, and airline companies — react to the figurants' role play. The quality of the overall problem resolution is evaluated by the national civil aviation regulator. We postulate that the closer the figurants' staging corresponds to reality, the more relevant the simulation exercise will be in training professionals involved in resolving an actual accident. To our knowledge, very little literature focuses on improving the performance of figurants (research objective). In this research, we conducted a fieldwork study (methodology) during a recent official exercise at Sion Airport in Switzerland. Based on the fieldwork analysis (results), we propose a new staging model (findings) to improve similar simulation exercises (implication).
\end{abstract}

Keywords-airport regulation; aircraft crash simulation; preventive risk management; service blueprinting; simulation staging

I.

INTRODUCTION

Every two years, the FOCA (Federal Office of Civil Aviation) requires Swiss international airports to carry out a crisis-simulation exercise involving all airport stakeholders (police, fire brigade, rescue services, airport management and employees, hospitals, FOCA, etc.). This type of full-scale drill requires substantial preparation in order to train airport stakeholders to face and manage any type of crisis as well as possible. We postulate that the closer the figurants' staging corresponds to reality, the more relevant the simulation exercise will be in training professionals involved in resolving an actual accident. The exercise under study took place on Thursday, October 25, 2018, from 7am to 5pm, at Sion International Airport. Eighty-four students from the University of Applied Sciences and Arts Western Switzerland (HES-SO) were cast for the whole day with precise roles to play according to an airport crisis scenario. Since the whole exercise is based on the notion of surprise, the specific roles were assigned to registered students at the last minute. Consequently, students had no prior knowledge of their role in the exercise, but they were ready to invest themselves throughout the whole day.

Sion Airport was created in 1935; two years later, it became a highly strategic location for military services. Commercial flights were introduced at the airport in the 1990s, and business flights have gained a lot of importance since then. In 2013, it was announced that the Swiss Army was going to leave its quarters in Sion. Consequently, over the last two years, the airport has become a fully commercial hub for international flights. Helvetic Airways, Swiss International Air Lines, and other charter companies are frequent users of the air strips. The Sion Airport is located in the midst of potential destinations of the Swiss Alps. Many customers can arrive in Sion and travel to Crans-Montana, Verbier, or Zermatt in a short time.

In order to remain a competitive airport in the commercial flights market, many strict controls and procedures must be enacted and conducted. A commercial airport must conform to many critical regulatory tests, which can determine the future of the organization or even force its closure. In this paper, we will focus on a very important test procedure that is conducted to ensure the airport keeps its license to operate. This test must be conducted every two years to assess the behavior of security stakeholders in case a crash happens at Sion Airport.

The rehearsal process of an aircraft crash simulation closely resembles practicing music scales, training in a sport, rehearsing a scene from a play, or following a dance routine. In a service experience (like going to the airport to fly on a plane), the routines are called "operating modes" and are orchestrated in such a way that the passenger undergoes a very complex process (baggage handling, security check, duty free shopping, boarding). In these ways, the airport service experience corresponds to a kind of general staging of both providers and clients. To provide high-quality service, new services must be rehearsed. Security and safety are part of these services. In this research, we want to contribute to the knowledge of airport security and safety by finding ways 
to improve the staging of figurants involved in an aircraft crash simulation, in order to provide more realism for this type of exercise.

This paper is organized as follows. In Section II, we present a brief review of the literature on crisis management and the related notion of realism in simulation drills and exercises. In Section III, we present the methodology that we applied to gather and analyze fieldwork data. In Section IV, we concentrate on the main results and findings. In Section V, we conclude with new guidelines for better taking into account the staging of figurants in order to make the simulation more realistic.

\section{LITERATURE REVIEW}

\section{A. Crisis Management}

According to Lucas et al. [1], crisis management skills include (a) problem solving, (b) situational awareness, (c) resource utilization, (d) communication, and (e) leadership. These competencies are acquired and trained through exercises and drills that are often called high-fidelity simulation (HFS), drills, or full-scale exercise.

"The Crisis Resources Management paradigm can be summarized as the articulation of principles of individual and crew behaviour in ordinary and crisis situations that focuses on skills of dynamic decision-making, interpersonal behaviour, and team management." [2]

Based on the literature, Henstra [3] identified 30 elements to evaluate an emergency program and to measure its performance. Some of these elements involve the public (e.g. mutual aid, planning for people with special needs, warning system, public education, volunteer management and rehabilitation). However, an evaluation based on these elements is usually done by experts and rarely by laymen. This is regrettable, since such an approach leads to functional problem resolutions and, consequently, does not properly take into account the true emotional state of people.

\section{B. Simulation to Train Crisis Management}

In crisis management, simulation is used to develop and train crisis management skills [4], [5], [6]. In general, studies in this area are solely focused on training crisis management teams [7]. This kind of drill is indeed essential to establish collaboration between multidisciplinary teams [8]. Simulation is also used in crisis management as research tool. For instance, in a quasi-experiment laboratory, researchers are able to develop new models and precepts regarding crisis management.

Simulation software (as opposed to "physical simulation") is also used more and more to train teams [9], [10], [11], [12]. The advantages of these computerized tools are: they do not affect the real system, they require fewer physical resources, they provide managers with a sound understanding of crisis situations, and many scenarios can be bested [10] at no extra cost. However, computerized simulations do not integrate the actual behavior of human beings.

In fact, both physical and computerized simulations do not take into account the perceptions of actors. All simulation approaches concentrate on the functional aspects of a given simulated scenario.

\section{High Fidelity Simulation in Healthcare}

In the healthcare sector, a simulation called High-Fidelity Simulation (HFS) is used to teach students and train teams. Numerous studies ([13], [14], [15], [16]) evaluate the impact of these exercises on students' skills and on their ability to work in teams [13]. Static mannequins, role playing, CPR mannequins, and other techniques have also been utilized for education [17]. The use of computer-enhanced mannequin simulators and standardized patients is common in training caregivers in high-fidelity simulations [18], [17].

In palliative medicine, role-play is often used as simulation tool, but this technique is considered expensive and time-consuming [19]. Compared to live-actor patients, simulators "have equivalent results in prompting critical actions in mass casualty drills and increase the perceived reality of such exercises" [20], [21]. However, even if HFSs are very advanced in the health sector, they do not take into account - for instance — the panicked behaviors of a crowd of public bystanders and injured passengers at an airport in a crisis situation.

\section{Realism in Simulation}

For crisis managers, the value of an exercise is determined by its degree of realism [22]. However, some researchers argue that trying to make a realistic exercise may in itself be unrealistic [23]. 
To assess the degree of realism of an exercise, research generally focuses on the opinion or perception of management or of the different teams of professionals (e.g. caregivers, firefighters, police) [24]. To our knowledge, very few studies focus on the point of view of the role-playing teams of figurants.

Scott et al. [23] argued that "the contribution of a real public can yield positive effects in the form of unpredictable reactions and behaviors that put extra pressure on the participants." In this research, we aim to learn more about taking into account real laymen behavior when designing aircraft crash simulations. III. METHODOLOGY

In a crisis simulation experiment, routines are called "operating modes" and are orchestrated in such a way that the passengers or bystanders at an airport (called "figurants") are properly directed by professionals through very complex processes. The simulation exercise corresponds to a kind of general staging of both professionals and figurants. The proper rehearsal of the exercise is thus critical to sufficiently prepare for actual crisis management.

This scenario has the objective of testing the reactions of security and safety professionals when a crash or an emergency situation occurs. The exploitation director was Mr. Stéphane Pillet, chief of the BTEE SA. His role was to create the aircraft crash scenario, to run the exercise, and to evaluate the airport's overall abilities in crisis management. The exercise was meant to identify shortcomings or areas for improvement in order to be able to meet obligations imposed by FOCA security and safety regulations.

The scenario of the simulation involved a crash between a commercial airplane and a helicopter that lost control in the landing phase and hit the crowd that was leaving the airplane. Several minutes later, another helicopter crashed into the ground on another part of the tarmac. This crisis situation was meant to test all the emergency procedures at Sion Airport. To reproduce the most realistic scenarios, the organization had to use 80 figurants to play passengers and injured people from the planes that crashed, as well as bystanders (for instance, relatives and friends of passengers waiting at the airport). The HES-SO proposed to hire out students from its nursing school and its tourism school for the day of the exercise. Eighty-four students were present on October 25, 2018, and each had a specific role to play, from fatally-injured passenger to friend that was waiting in Sion for an arrival. Our role was to organize the figurants before the event and then observe their behaviors during the day. We used an objective, external point of view to analyze how the students (the figurants) dealt with their roles during the exercise. With this realistic engagement with the official crash simulation, we had the opportunity to gather data about figurants' reactions based on focus groups, individual semi-directed interviews, photos (see Figure 1), and comprehensive film footages (Canal9, the regional television, had filmed the entire exercise with 13 cameras). All transcripts were analyzed with NVivo, and hypotheses were generated from the analysis. This work represents an exploratory research.

\section{FINDINGS}

Here, we describe in chronological order the main touchpoints of the exercise from start to finish. To visualize the entire staging of the exercise, we created an overall service blueprint [25] (see Figure 2) of the complete crash simulation. This blueprint also includes the pre-transaction, with information from the previous day, as well as the post-transaction, with the debriefing conducted immediately after the exercise. The line of visibility indicates what could be seen in terms of theater of operations - that is, the role played by the figurants, the reactions of the different professional bodies, and what went on backstage - to support the overall staging. Arrival of the participants. We quickly discovered that the procedure for figurants to receive their roles was too slow, causing a line at the entrance with considerable waiting time. The figurants did not complain too much, but some had hoped for a free breakfast. Greetings and official information for the day were only provided in French, and we could see that some German-speaking figurants could not understand everything. The orallycommunicated information wasn't loud enough, since no microphone was used.

Waiting time. Before being sent to the tarmac to start the simulation, some people were bored, mainly because they didn't properly understand their assigned role.

Exercise. The start of the exercise wasn't very clear, but people more or less understood that it had started, since the sirens had at some point activated. When the figurants arrived, a lot of them didn't properly play their roles and were thus rather passive. We saw that figurants were assembled in groups, and some figurants would influence the moves and behaviors of the different groups, as in "if he/she does it this way, I will too". After a bit of time, things went better, and figurants began to play their roles more realistically. In general, most figurants played their roles very well (especially the most injured ones; they came very early in the morning to be made up and disguised). Others were not motivated to properly play their distinctive role. Again, the waiting time was quite long for figurants whose role did not require specific help or treatment. Figurants were chatting together 
and could see with interest how the interventions on the tarmac evolved during the day. They liked the fact that beverages and sandwiches were available at the end of the exercise.

End of the exercise. The official finish was not very clear to everyone, like the start. Some figurants complained because they didn't know what to do or where to go. Thanks to 2 hours of data collection, after the exercise the figurants could share their experience in small focus groups as well as through individual interviews.

Selection of findings. The problem of language surfaced clearly. At Sion International Airport, the main language is French. Not everyone speaks fluent French, because the figurants are from a school with German classes as well. As a result, German-speaking students did not fully understand all the instructions before the simulation and during the crash situation. Therefore, it is recommended that people are greeted and given information in clear, loud French and German. This would help to prevent a lot of figurants from being confused and lost.

A significant number of figurants were lost and confused in general because of lack of clarity about when the exercise started and when it stopped. Therefore, it is recommended to properly signal the start of the crash simulation next time, perhaps with a clap (like the ones used for shooting movies).

The third major problem that created some friction among the figurants was the distribution of roles. At the time of meeting, all roles with a severe injury had already been assigned to students from Sion (the city close to the airport). Some of the figurants from Sierre were disappointed when they were assigned less-important roles. In addition, some students were not at all familiar with certain diseases, injuries, and states of mind. Therefore, it is recommended that the roles be distributed in advance, perhaps a few days. Figurants could thus do some research about how to react in case of emergency.

These three findings were chosen from among a long list of weaknesses identified during the exercise. We can thus draw the hypothesis that the staging of figurants and the staging of professionals should be directed independently but in parallel. Indeed, the purpose of figurants is to play a crisis scenario in the most realistic manner; the purpose of professionals is to play their own role in a realistic manner, since they need to be trained for extreme situations. Even if the exercise was a success as-is, we believe that these improvements would bring more realism to such exercises.

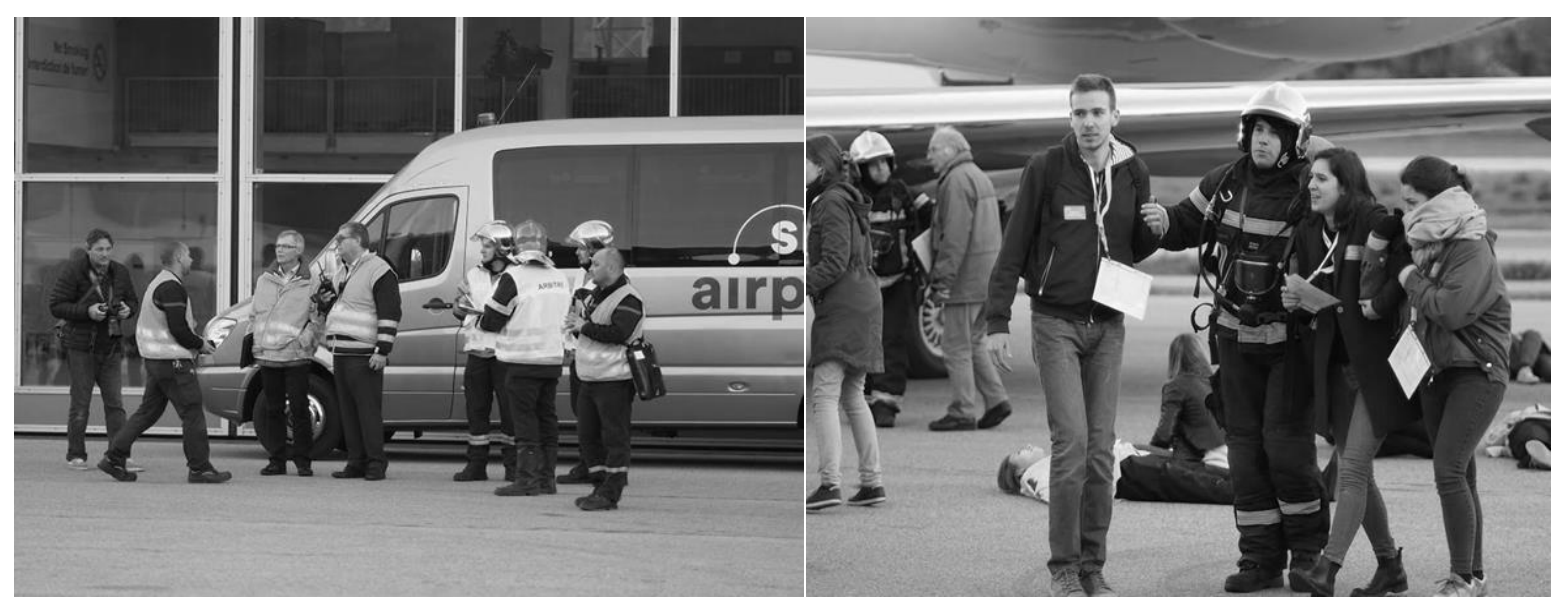

Figure 1. Two photos of the exercise, taken by one of the authors of this paper. 


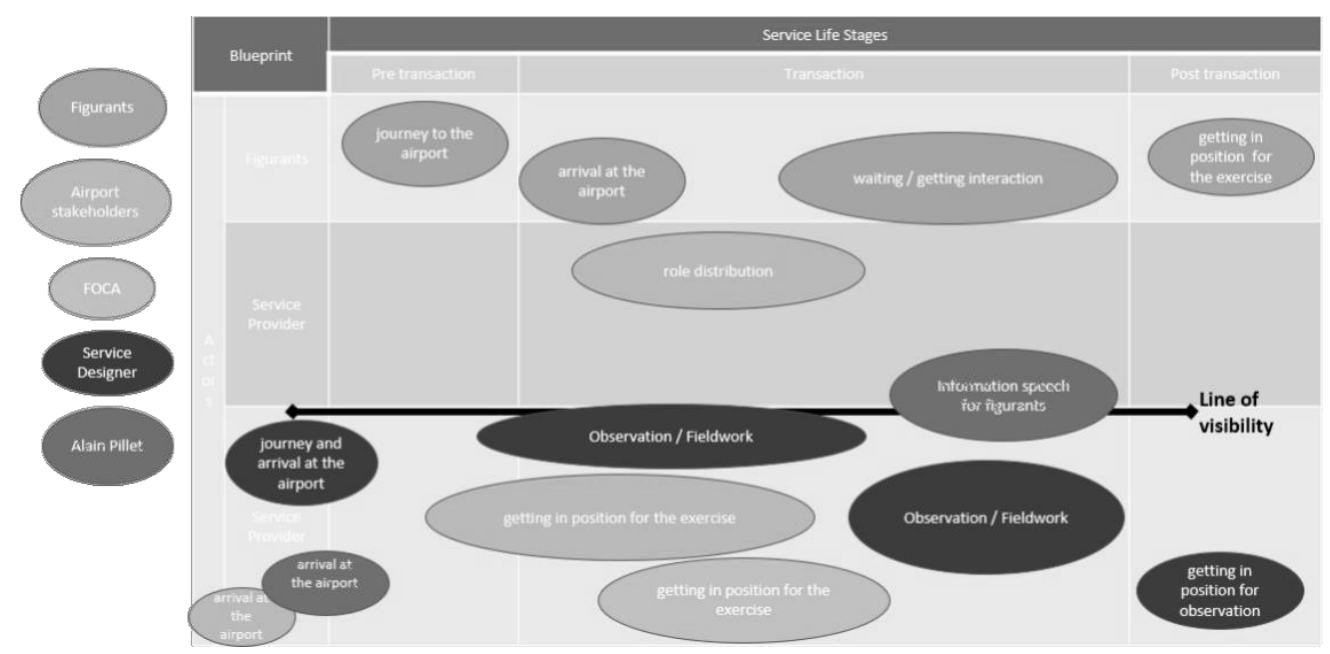

Figure 2. A service blueprint representation showing the overall staging of the entire exercise.

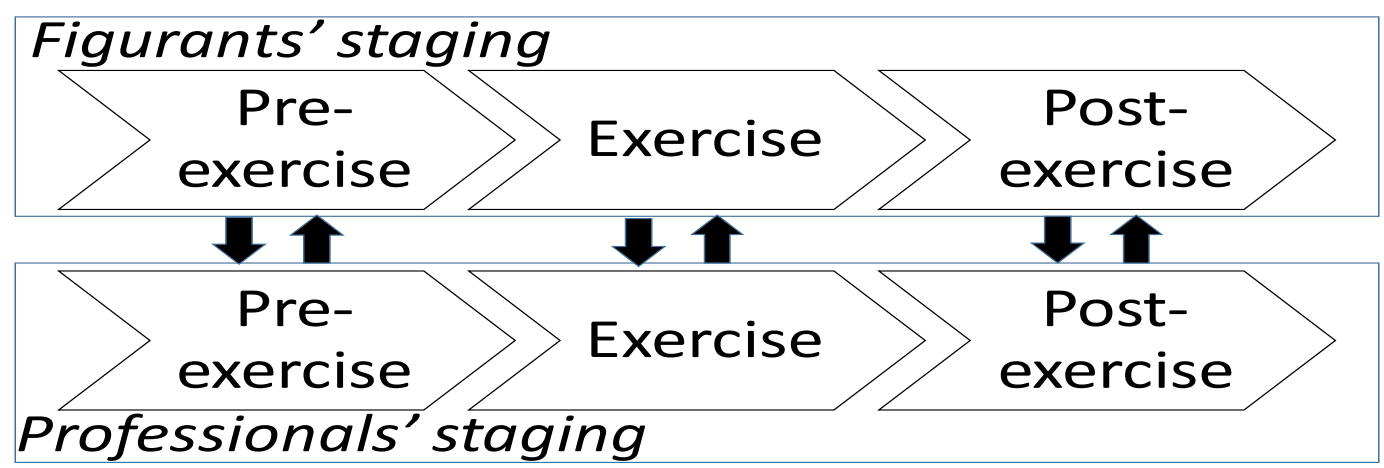

Figure 3. A new model for staging crisis simulation exercises, where stagings of figurants and professionals are run independantly.

\section{CONCLUSION}

Regular aircraft crash simulation exercises at an international airport are required be conducted. This makes it possible to see whether all safety and security actors are ready to deal with an airport accident in a coordinated manner. A whole range of scientific knowledge and professional expertise exists to develop this type of exercise to be maximally relevant. However, the emphasis is still on the problem-solving elements performed by safety and security professionals, and very little on the quality of the role-playing performed by figurants. Thanks to a mandatory exercise conducted at Sion airport, where figurants were recruited from HES-SO, we were able to conduct exploratory research to identify potential for improvement, in order to achieve more realism in staging a disaster scenario. The main finding of this qualitative field research is that figurants should be directed by an expert with a background in human sciences who is independent of the technical direction of the exercise. In addition, just as the execution of the exercise for professionals goes through three general phases - preparation (pre-exercise), conduct (exercise), evaluation and debriefing (post-exercise) - the figurant group should go through these three phases, in a parallel manner (see Figure 3). Such a systematic and documented approach would allow for better role-playing in this type of exercise, which should in turn improve the realism of future crisis simulations.

\section{ACKNOWLEDGMENT}

This research was supported by Stéphane Pillet, General Director of BTEE SA, who acted as our gatekeeper and sponsor. We thank our colleagues Professors Sandra Grèzes and Vincent Grèzes from HES-SO Valais-Wallis whose insight, expertise and assistance made this study possible. We would also like to show our gratitude to Aaron Andenmatten, Nicolas Mari and Nina Meyer for their active involvement in the organization of this simulation. 


\section{REFERENCES}

[1] A. Lucas and M. Edwards, "Development of crisis resource management skills: A literature review." Clinical Simulation in Nursing, vol. 13, no 8, 2017, pp. 347-358.

[2] D.M. Gaba, "Crisis resource management and teamwork training in anaesthesia," British Journal of Anaesthesia, vol. 107, no 3, 2010, pp. 3-6.

[3] D. Henstra, "Evaluating local government emergency management programs: What framework should public managers adopt?," Public Administration Review, vol. 70, no 2, 2010, pp. 236-246.

[4] A. Boin, C. Kofman-Bos, and W. Overdijk, "Crisis simulations: Exploring tomorrow's vulnerabilities and threats," Simulation and Gaming, vol. 35, no. 3, 2004, pp. 378-393.

[5] B. Robert and C. Lajtha, "A new approach to crisis management," Journal of contingencies and crisis management, vol. 10, no 4, 2002, pp. 181-191.

[6] K.P. Yusko and H.W. Goldstein, "Selecting and developing crisis leaders using Competency - Based simulations," Journal of contingencies and crisis management, vol. 5, no 4, 1997, pp. 216-223.

[7] D. Smith, "For whom the bell tolls: Imagining accidents and the development of crisis simulation in organizations," Simulation and Gaming, vol. 35, no 3, 2004, pp. 347-362.

[8] A.M. Morrison and A.M. Catanzaro, "High - fidelity simulation and emergency preparedness," Public Health Nursing, vol. 27, no 2, 2010, pp. 164-173.

[9] M.M.H. Quanjel, A.J. Willems, and A.N. Talen, "CRISISLAB: Evaluation and improvement of crisis management through simulation/gaming," Simulation and Gaming, vol. 29, no 4, 1998, pp. 450-455.

[10] P.K. Kwok, B.K. Chan, and H.Y. Lau, "A Virtual Collaborative Simulation-based Training System," Proc. of the 10th International Conference on Computer Modeling and Simulation, ACM, 2018, pp. 258-264.

[11] I. Heldal, "Simulation and serious games in emergency management: experiences from two case studies," Proc. Virtual System and Multimedia (VSMM), IEEE, 2016, pp. 1-9.

[12] A. Khorram-Manesh, J. Berlin, and E. Carlström, "Two Validated Ways of Improving the Ability of Decision-Making in Emergencies; Results from a Literature Review," Bulletin of Emergency and Trauma, vol. 4, no 4, 2016, pp. 186-196.

[13] T. Munangatire and N. Naidoo, "Exploration of high-fidelity simulation: Nurse educators' perceptions and experiences at a school of nursing in a resource-limited setting," African Journal of Health Professions Education, vol. 9, no 1, pp. 44-47.

[14] J.T. Paige, V. Kozmenko, T. Yang, R.P. Gururaja, C.W. Hilton, I. Cohn, and S.W. Chauvin, "Attitudinal changes resulting from repetitive training of operating room personnel using high-fidelity simulation at the point of care," The American Surgeon, vol. 75, no 7, 2009, pp. 584-591.

[15] D.D. Garbee, J.T. Paige, L.S. Bonanno, V.V. Rusnak, K.M. Barrier, L.S. Kozmenko, T.K Nelson, et al., "Effectiveness of teamwork and communication education using an interprofessional high-fidelity human patient simulation critical care code," Journal of Nursing Education and Practice, vol. 3, no 3, 2012, pp. 1-12.

[16] M. Anderson, M..L. Bond, T.L. Holmes, and C.L. Cason, C. L., "Acquisition of simulation skills: Survey of users," Clinical Simulation in Nursing, vol. 8, no 2, 2012, pp. 59-65.

[17] P.G. Sanford, "Simulation in nursing education: A review of the research," The Qualitative Report, vol. 15, no 4, 2010, pp. 1006-1011.

[18] M. Reznek, R. Smith-Coggins, S. Howard, K. Kiran, P. Harter, P., Y. Sowb, T. Krummel, et al.., "Emergency medicine crisis resource management (EMCRM): pilot study of a simulation-based crisis management course for emergency medicine," Academic Emergency Medicine, vol. 10, no 4, 2003, pp. 386389.

[19] L. Evans and M. Taubert, "State of the science: the doll is dead: simulation in palliative care education," BMJ supportive and palliative care, 2018, pp. 1-3.

[20] B. Gillett, B. Peckler, R. Sinert, C. Onkst, S. Nabors, S. Issley, B. Arquilla, et. al., "Simulation in a disaster drill: Comparison of high - fidelity simulators versus trained actors,” Academic Emergency Medicine, vol. 15, no 11, 2008, pp. 1144-1151.

[21] C.M. Schulz, M. Skrzypczak, S. Raith, D. Hinzmann, V. Krautheim, F. Heuser, C. Lipp, et al., "Highfidelity human patient simulators compared with human actors in an unannounced mass-casualty exercise," Prehospital and Disaster Medicine, vol. 29, no 2, 2014, pp. 176-182.

[22] A. Enander, S. Hede, S. and Ö Lajksjö, "Why Worry? Motivation for Crisis Preparedness Work among Municipal Leaders in Sweden,” Journal of Contingencies and Crisis Management, vol. 23, no 1, 2015, pp. 1-10. [23] D. Scott, C. Brandow, J. Hobbins, S. Nilsson, and A. Enander, "Capturing the citizen perspective in crisis management exercises: possibilities and challenges. International Journal of Emergency Services," vol. 4, no 1, 2015, pp. 86-102.

[24] R.W. Perry, "Disaster exercise outcomes for professional emergency personnel and citizen volunteers," Journal of contingencies and crisis management, 2004, vol. 12, no 2, pp. 64-75. 
[25] S. Barbieri, E. Fragnière, M.S. Sitten, and G. Zambrano, "Proposal of a methodology to integrate the human factor in the service blueprint," Journal of Advanced Management Science, vol. 1, 2013, pp. $207-213$. 